\title{
Solar thermal power generation technology research
}

\author{
Yudong Liu ${ }^{1 *}$, Fangqin $\mathrm{Li}^{1}$, and Jianxing Ren ${ }^{1}$, Guizhou Ren ${ }^{1}$, Honghong Shen ${ }^{1}$, and Gang Liu ${ }^{1}$ \\ ${ }^{1}$ Colleg of Energy and Mechanical Engineering, Shanghai University of Electric Power, Shanghai, China
}

\begin{abstract}
China is a big consumer of energy resources. With the gradual decrease of non-renewable resources such as oil and coal, it is very important to adopt renewable energy for economic development. As a kind of abundant renewable energy, solar power has been widely used. This paper introduces the development status of solar power generation technology, mainly introduces solar photovoltaic power generation technology, briefly describes the principle of solar photovoltaic power generation, and compares and analyzes four kinds of solar photovoltaic power generation technology, among which photovoltaic power generation technology is the most mature solar photovoltaic power utilization technology at present.
\end{abstract}

\section{Introduction}

At present, with the development of the global economy consuming a lot of fossil fuels, fossil energy represented by oil is increasingly exhausted, leading to the rapid growth of greenhouse gas emissions, people have to face the problem of global greenhouse effect and resource shortage. How to reduce greenhouse gas emissions has become an urgent problem for the whole world [1].China has a great demand for energy, and the energy industry supports the rapid development of China's economy. However, most of the energy resources have the problems of large waste and low utilization rate in the development and utilization. Solar power generation has attracted extensive attention because of its advantages such as wide source, low operating cost and no pollution to the environment. The large-scale application of solar power can reduce the proportion of fossil energy in China's energy consumption structure and improve the energy structure [2]. Solar power generation technology is an important technology to alleviate energy crisis and an effective way to solve environmental pollution.

\section{Solar power generation technology}

At present, solar power generation technology is mainly divided into two types, one is solar light power generation technology, and the other is solar Solar-thermal power generation technology.Solar power generation mainly includes photovoltaic power generation, photochemical power generation, optical induction power generation and biological power generation, among which photovoltaic power generation technology is widely used. Photovoltaic power generation has the characteristics of high efficiency, low pollution and good flexibility, but photovoltaic panels have many defects such as high pollution, high energy consumption and large space occupation [3-4].Solar thermal power generation technology mainly includes tower solar thermal power generation system, trough solar thermal power generation system and dish solar thermal power generation system [5].Than solar-thermal power generation is the sun point-blank light energy through the adoption of many a mirror together, make the heat transfer fluid in the heat pipe heat continuously heating up, and to transfer heat to high temperature steam produced in the steam generator, and then by the power generating units of a renewable energy application technology, it has low cost, stable output power and power generation system of continuous adjustable, and long service life, no pollution and other advantages, therefore, solar-thermal power generation is more competitive power generation technology [6].

\section{Technical analysis of solar thermal power generation}

Since the oil crisis in the early 1970s, the major developed countries in the world, such as the United States, Spain, Germany, Switzerland, France, Italy and Japan, have taken solar thermal power generation technology as the focus of national research and development, gradually started to develop solar thermal power generation on a large scale, and established a large number of experimental power stations. In the last 20 years, there have been about 20 solar thermal power stations (over $500 \mathrm{~kW}$ ) built around the world, and some of them have been put into commercial operation [7]. By the end of 2018, the installed capacity of global solar thermal power generation has reached 6.The installed capacity of $3 \mathrm{GW}$ in the United States, Spain and other countries has been successfully put into commercial operation. Although China's research on photovoltaic power generation is relatively late, through in-depth research, tests and verification, China's own photovoltaic 
power generation technology has developed rapidly, and the installed capacity of photovoltaic power generation in China has reached $79000 \mathrm{~kW}$.

According to the different power generation principles, Solar-thermal power generation includes concentrated Solar-thermal power generation, solar semiconductor temperature difference power generation, solar chimney power generation, solar pool power generation and solar thermal acoustic power generation. Among them, concentrated Solar-thermal power generation is the most commercial use of the most promising technology. Among them, concentrated Solar-thermal power generation is the most commercial use of the most promising technology. According to the different ways of condensing, the condensing Solar-thermal power generation can be further divided into two systems: point focusing and line focusing. The point focusing system mainly includes tower type Solar-thermal power generation and disc type Solar-thermal power generation. The line-focusing system mainly includes trough Solar-thermal power generation and linear Fresnel Solar-thermal power generation [8].

\subsection{Principle of solar thermal power generation}

Solar-thermal power generation principle is that through the reflectors, such as condenser of heat exchanger will collect solar radiation into heat energy collection of hot charging, used to heat the heating device inside the heat transfer medium, such as heat conduction oil or molten salt with a heat exchange device, heat transfer medium

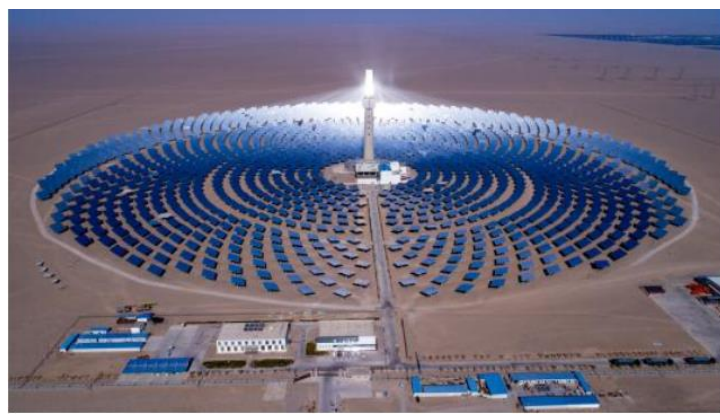

Figure 1. Tower solar thermal power generation system

The main features of the tower solar thermal power generation system are as follows :(1) the concentration-light ratio usually achieved by the tower solar thermal power generation system is $300 \sim 1,500$, and the operating temperature can reach $1,000 \sim$ $1,500{ }^{\circ} \mathrm{C}[7] .(2)$ the tower Solar-thermal power generation system has short heat transmission distance, low heat loss and high comprehensive efficiency, which can reach about $14 \%$ at present;(3) solar tower power generation is suitable for large-scale and large-capacity commercial application;(4) the tower Solar-thermal power generation system has large one-time investment, complex device structure and control system, and high cost [8]. water heated to high temperature and high pressure steam, steam to drive a turbine driven generator to produce electricity. This through the "light - heat - mechanical electrical energy transformation process of the realization of power generation technology is known as concentrated solar power technology. The principle and basic equipment composition of solar thermal power generation are basically the same as those of fossil fuel power plants. The biggest difference is that the heat sources used for power generation are different. Solar thermal power generation USES clean and abundant solar energy [9].

\subsection{Solar thermal power generation technology types}

\subsubsection{Tower solar thermal power generation system}

Tower type solar thermal power generation is also known as concentrated solar thermal power generation. It takes the form of a number of arrays of mirrors that reflect solar radiation onto a solar receiver located at the top of the tower, heating the working medium to produce superheated steam, which drives a turbine generator to generate electricity and convert the absorbed solar energy into electricity. Tower solar thermal power generation is mainly composed of four parts: mirror field, heat exchange system, heat storage device and steam turbine generator [10]. Tower solar thermal power generation system is shown in figure 1 .

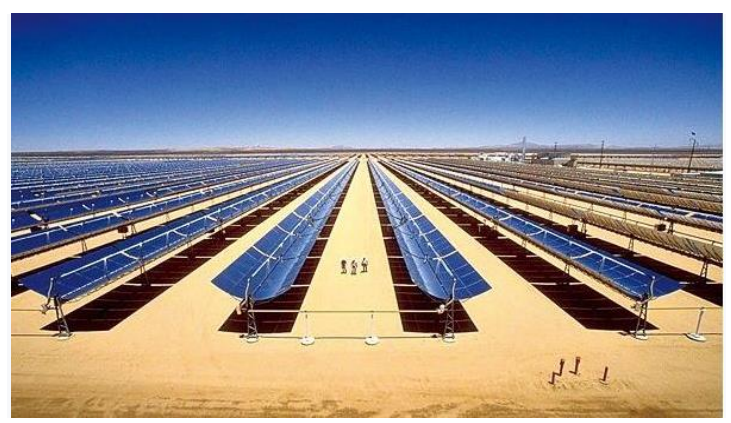

Figure 2. Trough solar thermal power generation system

\subsubsection{Trough solar thermal power generation system}

Trough type solar thermal power generation system is to use the groove parabolic mirror concentrated solar thermal power generation system. The focusing mirror from the point of view of geometry is the parabola translation and formation of the parabolic trough type, it will be the sunlight in a line, in this article the focal online installation has tubular collector, after focusing to absorb solar radiation energy, and often many groove parabolic series-parallel into concentrating collector array [11]. Slot to track one dimensional parabolic face more solar radiation (axis equipment placed between the 
north and the south, then what the track).Its geometric concentration ratio is between 10 and 100 , and the temperature can reach about $400{ }^{\circ} \mathrm{C} \mathrm{[7]}$. The trough solar thermal power generation system is shown in figure 2.At present, trough power station has the lowest operation risk and generation cost, and the most commercial value, which is suitable for medium-low temperature solar thermal power generation system [12].

\subsubsection{Disc solar thermal power generation system}

Disc type solar thermal power generation system using disk parabolic mirror to focus the sun's rays, installed in the focus of working medium heat absorber absorbs solar radiation heat absorption of heat, heat absorption working medium and working medium of the steam generator heat exchange water, generated by the high temperature and high pressure steam driving turbine generator [13], disc type solar thermal power generation system as shown in figure 4.The advantages of the system are that the concentrator ratio can reach 3,000 [14], the receiver's heat absorption area is small, the working medium's heat collection temperature is > $800{ }^{\circ} \mathrm{C}$, and the system efficiency can reach $29.4 \%$ at most.

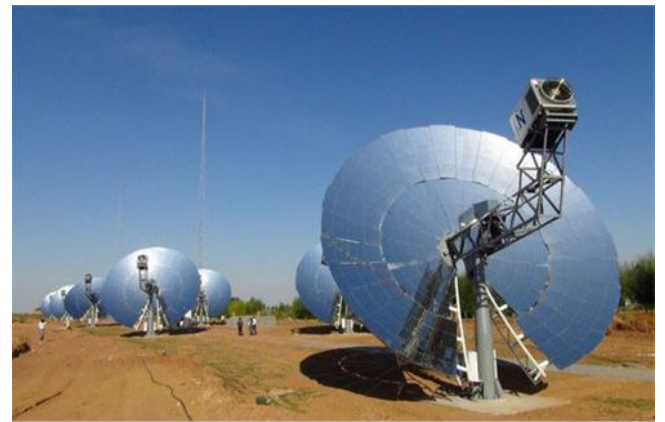

Figure 3.Disc solar thermal power generation system

\subsubsection{Linear Fresnel type solar thermal power generation system}

Linear Fresnel thermal power generation system is similar to parabolic trough thermal power generation. It consists of many horizontal mirrors rotating on a single axis, which form a rectangular mirror to automatically track the sun. The reflected sunlight is gathered on the collector tube, and the fluid medium in the heating tube generates steam directly or indirectly, which drives the steam turbine unit to generate electricity. Linear Fresnel thermal power generation system is relatively simple, and the mirror can adopt plate mirror, which has lower cost but lower system efficiency. The structure of the system is relatively simple, the transmission mechanism is easy to operate, and the collector pipe can be made of steel.Therefore, the cost is lower than the tank system, so it can be applied in many places with its own characteristics, such as heating water/steam, providing steam to buildings and factories (temperature range: $80^{\circ} \mathrm{C}$ $\sim 250{ }^{\circ} \mathrm{C}$ ), using small and medium-sized heat engines for medium-low temperature power generation, heating, refrigeration and other multi-generation, solar desalination and so on. However, the focus of this heat collection system is relatively small, so the temperature rise is limited, the heat collection tube needs to absorb heat and dissipate heat at the same time, so the heat loss in operation is relatively large, and the system efficiency is lower than that of the tank system. At present, the application scope is small, and there are not many demonstration projects.

\subsection{Comparative analysis of solar thermal power generation technology}

The characteristics of the above four solar photovoltaic power generation technologies are compared and analyzed [7,9], and the results are shown in table 1.

Table 1. Comparison of photothermal power generation technologies

\begin{tabular}{|c|c|c|c|c|}
\hline Project & Tower & Trough & Disc & Fresnel \\
\hline Heat transfer medium & $\begin{array}{l}\text { Water/steam, } \\
\text { molten salt }\end{array}$ & $\begin{array}{l}\text { Water/steam, molten } \\
\text { salt, heat conducting oil }\end{array}$ & Molten salt & Water/steam \\
\hline Focusing technology & Point focusing & Line focusing & Point focusing & Line focusing \\
\hline Scale (MW) & $30-100$ & $30-350$ & $5 \sim 25$ & $10-320$ \\
\hline Energy storage & Yes & Yes & No & Yes \\
\hline Application & $\begin{array}{l}\text { Grid-connected } \\
\text { power generation }\end{array}$ & $\begin{array}{l}\text { Grid-connected power } \\
\text { generation }\end{array}$ & $\begin{array}{l}\text { Small capacity decentralized } \\
\text { power generation, remote areas } \\
\text { independent system power supply }\end{array}$ & $\begin{array}{l}\text { Small } \\
\text { application } \\
\text { range }\end{array}$ \\
\hline Concentrated ratio & $300-1500$ & $50-100$ & $600-3000$ & $25-150$ \\
\hline Unit efficiency & $23 \%$ & $21 \%$ & $30 \%$ & $20 \%$ \\
\hline
\end{tabular}

As can be seen from table 1, trough Solar-thermal power generation has the most extensive application range, up to $30-350 \mathrm{mw}$, and is suitable for middle and low temperature heating, with a generation efficiency of up to $21 \%$. The concentration-light ratio of the tower solar thermal power system can reach $300 \sim 1,500$, and the operating temperature can reach $1,000 \sim$ 1,500 ${ }^{\circ} \mathrm{C}$. The tower Solar-thermal power generation system can be connected to the grid, and the power generation efficiency can reach about $23 \%$ at present. 
However, the performance, initial investment and operation cost of the tower Solar-thermal power generation system are not sufficiently commercialized, and the tower power generation cost is high. The concentrator ratio of disc Solar-thermal power generation is 600-3000, the receiver's heat absorption area is small, the working medium's heat collection temperature is $>$ $800{ }^{\circ} \mathrm{C}$, and the system efficiency is up to $30 \%$. However, the structure of disc solar collector is relatively complex, and the reliability needs to be strengthened. Fresnel Solar-thermal power generation system is characterized by simple system, direct use of thermal conductivity to generate steam, its construction and maintenance cost is relatively low.However, its focus is relatively small, the temperature rise is limited, and the heat loss during operation is relatively large.Overall, trough solar thermal power generation system is the most mature in technology, easy to realize, the overall cost is the lowest, and the heat collection temperature is moderate, more suitable for low and medium temperature solar thermal power generation system.

\section{Conclusion}

To sum up, solar energy is a widely used power generation technology, and various solar power generation technologies can meet the different needs of the society and regions for solar power generation.Among them, solar thermal power generation technology avoids expensive silicon photoelectric conversion process, which can greatly reduce the cost of solar power generation.At the same time, the output power of Solar-thermal power generation is continuous and stable, which has the potential to become the power of base load. Among them, the technology of trough Solar-thermal power generation system has been mature, which is applicable to the widest range and has basically realized commercialization.

\section{References}

1. Luo CX.(2010) The popularization and prospect of solar power generation . Sino-Global Energy, 15(11):33-39.

2. Wang DL,Zhang C,Yang Y, etc. (2019) Research progress of thermochemical energy storage system based on solar thermal power generation. Thermal Power Generation,48(07):1-9.

3. M. Seitz, M. Johnson, S. Hübner. (2017) Economic impact of latent heat thermal energy storage systems within direct steam generating solar thermal power plants with parabolic troughs. Energy Conversion and Management, 143.

4. Yang ML, Yang XX, Lin RM, etc. (2008) Solar thermal power technology and systems. Journal of Engineering for Thermal Energy and Power, (3): 221-228.
5. Li J. (2017) Research and development analysis of solar power generation technology. China Strategic Emerging Industry, (12):17-18.

6. Yu NJ. (2019)Numerical study on heat transfer characteristics of molten salt at high temperature in the heat absorption tube of tower solar photovoltaic power generation. Xi'an University of Technology.

7. Gao S,Hou HJ. (2009) Solar thermal power system analysis. Water Conservancy \& Electric Power Machinery, 31(01):70-74.

8. Xin PY. (2015) Comprehensive evaluation and application prospect of solar power generation technology. North China Electric Power University.

9. Zhang FJ,Li FM. (2019) Review on technological development of Concentrating Solar Power. Boiler Manufacturing, (04):33-36+46.

10. Guo LP. (2013) Analysis on the technical scheme of tower and trough solar power generation. Mechanical Engineer, (07):44-46.

11. Yuan JL, Lin RM, Jin HG, etc. (2007) Solar thermal power generation system and classification. Solar Energy, (4):30 -33.

12. Gu YJ, Geng Z, Zhang C, etc. (2017)Review on key technologies of concentrating solar thermal power generation systems. Thermal Power Generation, 46(06):6-13.

13. Li ZW. (2019) Numerical study on optical properties and heat transfer characteristics of disc-type solar heat absorber. Taiyuan University of Technology.

14. JAFFE L D. (1989) Test results on parabolic dish concentrators for solar thermal power systems. Solar Energy, 42(2): 173-187.

15. Chen J, Liu JZ, Shen WJ, et al. (2012) Status quo in research of solar energy thermal power generation system $[\mathrm{J}]$. Thermal Power Generation, 41(4):17-22. 